\title{
Molecular Detection and Subtyping of New Delhi Metallobetalactamases (NDM-1) in Clinical Isolates of Escherichia coli and Klebsiella pneumoniae in a Tertiary Care Hospital, South India
}

\author{
M. Uma Maheswari* and Appalaraju \\ Department of Microbiology, PSGIMS \& R, Coimbatore, India \\ *Corresponding author:
}

\begin{abstract}
A B S T R A C T

\begin{tabular}{|l|}
\hline Key w or d s \\
NDM-1- \\
$\begin{array}{l}\text { Newdelhi } \\
\text { metallo- } \\
\text { betalactamases. }\end{array}$ \\
\hline Article Info \\
\hline $\begin{array}{l}\text { Accepted: } \\
\text { 25 April } 2017 \\
\text { Available Online: } \\
\text { 10 May } 2017\end{array}$ \\
\hline
\end{tabular}

Enterobacteriaceae are inhabitants of human, animal gastrointestinal tract and various other environmental sites. Escherichia coli and Klebsiella pneumoniae initially responded to betalactam antibiotics but there was an increase in resistance to betalactam antibiotics due to beta lactamase produced by them. Resistance to carbapenems has now become more prevalent due to production of carbapenemases. NDM-1 is a novel metallo betalactamase that is capable of hydrolysing all beta lactam antibiotics except Aztreonam. It was aimed for Molecular detection and subtyping of NDM-1 in Escherichia coli and Klebsiella pneumoniae. Hundred carbapenem resistant isolates (42 isolates of Escherichia coli and 58 isolates of Klebsiella pneumoniae) were selected randomly for Molecular detection and sequencing of subtypes. A total of $82 \%$ strains were found to be NDM-1 positive yielding $475 \mathrm{bp}$ amplicon by molecular methods. Nine samples were sequenced for subtypes, of which five were NDM-1, two were NDM-4, and remaining two were NDM-3, and NDM-5.Sequencing and finding out of the subtypes may help to select new drug targets and design novel antibiotics.
\end{abstract}

\section{Introduction}

Enterobacteriaceae are inhabitants of wide variety of niches, including the human, animal gastrointestinal tract and various other environmental sites. The family Enterobacteriaceae includes a large number and diversity of genera.

During the past decade, there has been an emergence of carbapenems-resistant Enterobacteriaceae that produce carbapenamases, enzymes that efficiently hydrolyze carbapenems, as well as most $\beta$ lactam drugs (Queenan et al., 2007). New Delhi Metallo-beta-lactamases-1 (NDM-1) are one such carbapenamase that makes bacteria resistant to a broad range of betalactam antibiotics. These include the antibiotics of the carbapenems family, which are a mainstay for the treatment of antibioticresistant bacterial infections. Bacteria that produce carbapenamases are often referred to in the news media as "superbugs" because infections caused by them are difficult to treat.

Such bacteria are usually susceptible only to polymyxins and tigecycline. NDM-1 was first detected in a Klebsiella pneumoniae isolate from a Swedish patient of Indian origin in 2008. It was later detected 
in bacteria in India, Pakistan, the United Kingdom, the United States, Canada, and Japan (Kumarasamy et al., 2010).

\section{Materials and Methods}

\section{Study population}

After Ethical clearance from the institution, the study was conducted between April 2014 and August 2015 on various clinical samples. Two thousand and forty two isolates of Escherichia coli and thousand hundred and ninety two isolates of Klebsiella pneumoniae, were identified by IMViC tests. Of which Five hundred and sixty isolates of Klebsiella pneumoniae (47\%) and hundred and forty eight isolates of Escherichia coli (7\%) were resistant to carbapenems. Among them hundred isolates were selected randomly for the study (42 isolates of Escherichia coli and 58 isolates of Klebsiella pneumoniae)

Isolation of carbapenem resistant Escherichia coli and Klebsiella pneumoniae

The isolates were screened for the production of Carbapenam resistance as per CLSI 2014, using Ertapenem 10ug and Merapenam 10ug disc. The zone diameter of inhibition less than $19-21 \mathrm{~mm}$ for Ertapenem and less than 16$21 \mathrm{~mm}$ for Merapenam indicates Carbapenemase production. As per CLSI 2014 Ertapenem non susceptibility was the most sensitive indicator of Carbapenem resistance. Isolates were also tested by automated identification system (VITEK 2) for carbapenem resistance, based on Minimal Inhibitory Concentration. Among them a total of 100 isolates (42 isolates of Escherichia coli and 58 isolates of Klebsiella pneumoniae) were selected randomly for molecular study.

\section{DNA extraction}

The isolates were incubated overnight at $35^{\circ} \mathrm{C}$ in Luria broth. About 2-3 $\mathrm{ml}$ of inoculum was centrifuged at 5000rpm for 10 minutes. After centrifugation the supernatant was discarded and the pellet was taken in a sterile Eppendorf tube. The pellets were resuspended in distilled water and kept in a water bath at $95^{\circ} \mathrm{C}$ for 20 minutes. It was then cooled and centrifuged at $5000 \mathrm{rpm}$ for 10 minutes. The supernatant was the extracted DNA and is stored at $-20^{\circ} \mathrm{C}$.

\section{Polymerase chain reaction}

The extracted DNA was mixed with forward, reverse primers for NDM-1, master mix and PCR water and amplified in step one $A B$ applied Bio system Real time PCR machine.PCR cycle consists of the following steps (Jeremiah et al., 2014). Initial denaturation at $94^{\circ} \mathrm{C}$ for $3 \mathrm{~min}$, Denaturation at $94^{\circ} \mathrm{C}$ for $30 \mathrm{~s}$ Annealing at $60^{\circ} \mathrm{C}$ for 25 Extension at $72^{\circ} \mathrm{C}$ for $30 \mathrm{~s}$, Final extension at $72^{\circ} \mathrm{C}$ for $3 \mathrm{~min}$ for 30 cycles. The amplified products are stored at $-20^{\circ} \mathrm{C}$. Gel Electrophoresis was run. The images of the gel were captured by Gel doc and viewed. The presence of the NDM-1 gene was confirmed by the formation of bands at 475bp.

\section{Gene sequencing and blasting}

The amplied products which were confirmed for the presence of NDM-1 were sent for gene sequencing to Eurofins Genomics Bangalore. The sequenced genes were blasted using BIO EDIT software and results were interpreted in the NCBI (National centre for Biotechnology Information) website.

\section{Results and Discusion}

Two thousand and forty two isolates of Escherichia coli and thousand hundred and ninety two isolates of Klebsiella pneumoniae, were identified in various clinical samples during the study period, of which Five hundred and sixty isolates of Klebsiella pneumoniae (47\%) and hundred and forty 
eight isolates of Escherichia coli (7\%) were resistant to carbapenems. Among them Forty two isolates of Escherichia coli and Fifty eight isolates of Klebsiella pneumoniae were selected for molecular study.

\section{Polymerase chain reaction}

Among the hundred isolates, eighty two (82\%) were found to be NDM-1 positive (475bp) by PCR. Gel pattern of NDM-1 is depicted (Fig 1). Thirty seven (88\%) of Escherichia coli and Forty five Klebsiella pneumoniae (77\%) were NDM-1 producers.

\section{Subtypes of NDM-1}

Nine samples of amplified DNA (25ul) were sent randomly for sequencing at Euro fin genomics India pvt Ltd in Bangalore. Among them four were Escherichia coli and five were Klebsiella pneumoniae. The results send by the Eurofins Genomics were subjected to gene blasting using the BIO EDIT software and the sequence results were interpreted in NCBI (National centre for Biotechnology and Information) web site as shown in figures 2 and 3. On interpretation it was found that Amplicon-1, Amplicon -2, Amplicon -4, Amplicon -6 and 8 had amino acid sequences of NDM-1 and Amplicon -3 was NDM-5 and Amplicon -5 was NDM-3 and Amplicon -7 and Amplicon -9 were NDM-4. NDM-5 showed a point mutation variant differing from NDM-1 having a Met to Leu (M-L) substitution at 154 and Val to Leu (VL)substitution at 88. NDM-3 showed a point mutation variant differing from NDM-1 having substitution of Asp to Asn (D-N) at 95.NDM-4 differs from NDM-1 by a single amino acid substitution (M-L) at 154 (Met to Leu) which is shown in table 1.

Gram negative bacteria belonging to the family of Enterobacteriaceae are the most frequently isolated organisms from clinical specimens. They are incriminated in virtually any type of infectious diseases and recovered from any specimen received in the laboratory. Escherichia coli and Klebsiella pneumoniae cause sepsis, endotoxic shock, urinary tract infections, meningitis in neonates and pneumonia in immune compromised.

They are normally treated based on the antibiotic sensitivity, site of infection and comorbidity conditions (Longo et al., 2011). Escherichia coli and Klebsiella infections initially responded to betalactam antibiotics, but there was a dramatic increase in resistance to beta lactam antibiotics due to betalactamases produced by them. This resistance was superseded by use of second and third generation cephalosporins and combination of betalactam antibiotics with betalactamases inhibitors (Nosocomial burn wound infections, 2004).

Further with the emergence of ESBLs and Amp C resistance, carbapenems became the drug of choice. There has been a rapid increase in carbapenems resistance in Enterobacteriaceae in the recent years. The carbapenems resistance may be due to carbapenamases production, Efflux pump and Amp $\mathrm{C}$ enzyme production with membrane impermeability. However, carbapenamases (betalactamases) were found to be the predominant mechanism of this resistance. Among the newly emerged carbapenamases, New Delhi Metallo betalactamases (NDM-1) represents a war between the bugs and drugs.NDM-1 producing organisms are called super bugs (BorA et al., 2012).

NDM-1 was first reported in 2008 in Klebsiella pneumoniae and Escherichia coli. Both of them were recovered from a Swedish patient of Indian origin who was previously admitted in a hospital in New Delhi, India. Thereafter, NDM-1 has increasingly been reported from India and from several other parts of the world. 
Besides this, most of these NDM-1 positive bacteria are also resistant to a wide variety of Antimicrobials like aminoglycosides, flouroquinolones, macrolides and sulphonamides and carry several additional resistance mechanisms, leaving only few or no therapeutic options (Krishna, 2010). In our study period carbapenem resistance was observed in $47 \%$ of Klebsiella pneumoniae and $7 \%$ of Escherichia coli in our hospital.

As per CLSI 2014 Ertapenem is a good marker for detection of Carbapenems resistance as others do not predict this resistance well. We randomly selected 42 Escherichia coli followed by 58 Klebsiella pneumoniae which were carbapenems resistant for molecular analysis. Molecular tests are the most accurate and usually taken as Gold standard. In our study we used the following primers (475bp) to detect NDM-1 by conventional PCR. NDM Forward: 5'GGGCAGTCGCTTCC AACGGT and

\section{NDM Reverse: 5'- GTAGTGCTCAGTGTC GGCAT}

Amplification, sequencing and subsequent blasting were performed to identify the subtypes. Eighty-two (82\%) strains were found to be NDM-1 positive (475bp) of which Thirty seven (45\%) were Escherichia coli and Forty five were Klebsiella pneumoniae (54\%). The presence of NDM-1 has also been reported in Bangladesh, Australia, Netherlands, USA, Canada, Japan, and China indicating that blaNDM-1is widely spread all over the world (Berrazeg et al., 2014).

Table.1 DNA sequencing results of NDM-1 carbapenamase genes studied

\begin{tabular}{|l|l|l|}
\hline Amplicon & Aminoacid Substitution & Interpretation \\
\hline Amplicon-I & Aminoacid sequences of NDM-1 & NDM-1 \\
\hline Amplicon-2 & Aminoacid sequences of NDM-1 & NDM-1 \\
\hline Amplicon-3 & $\begin{array}{l}\text { Met to Leu (M-L) substitution at 154 and } \\
\text { Val to Leu (V-L)substitution at 88. }\end{array}$ & NDM-5 \\
\hline Amplicon-4 & Aminoacid sequences of NDM-1 & NDM-1 \\
\hline Amplicon-5 & Substitution of Asp to Asn (D-N) at 95. & NDM-3 \\
\hline Amplicon-6 & Aminoacid sequences of NDM-1 & NDM-1 \\
\hline Amplicon-7 & $\begin{array}{l}\text { Single amino acid substitution (M-L ) at } \\
154 \text { (Met to Leu). }\end{array}$ & NDM-4 \\
\hline Amplicon 8 & Aminoacid sequences of NDM-1 & NDM-1 \\
\hline Amplicon 9 & $\begin{array}{l}\text { Single amino acid substitution (M-L ) at } \\
154 \text { (Met to Leu). }\end{array}$ & NDM-4 \\
\hline
\end{tabular}


Fig.1 Gel electrophoretic analysis of amplified NDM-1 gene products

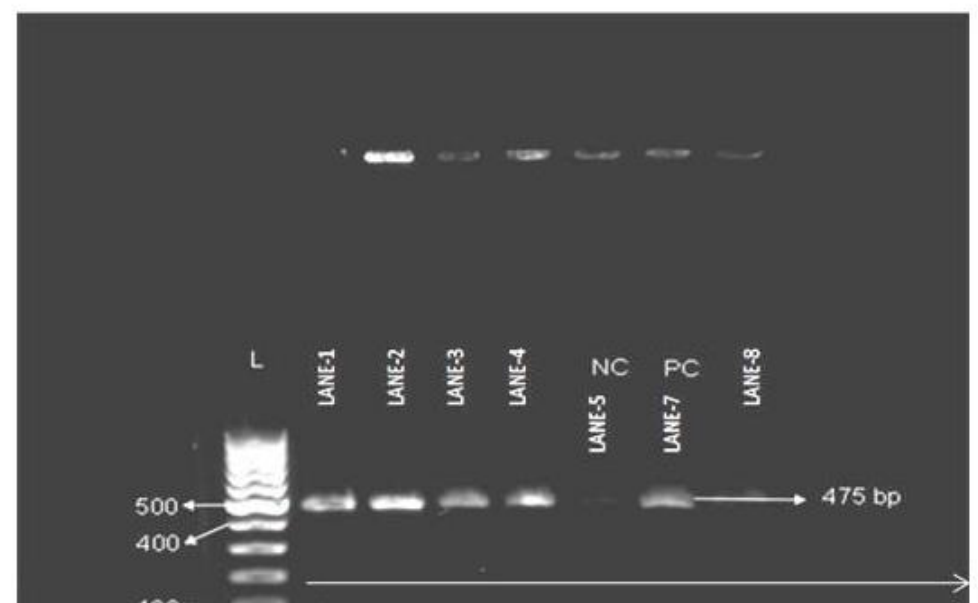

$100 \longleftarrow$

\section{LADDER}

NDM-1 GENE

LANE-1 \&2-Escherichia coli (+ve for NDM-1);LANE 3\&4-Klebsiellapnemoniae(+ve for NDM-1)

Fig.2 DNA sequencing results of amplified NDM-1

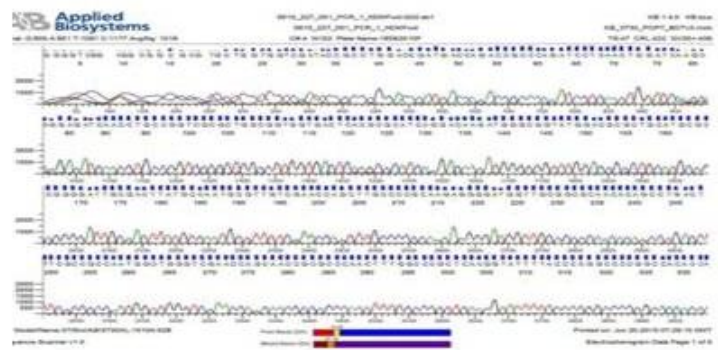

$>015$ 227_14_AMIIIICON_I

AACGATTGGCCTIGCTGTCCTIGATCAGGCAGCCACCAAAAGCGATGT CGGTGCOGTCGATCOCAACGGTGATATTGTCACTGGTGTGGCCGGGGC CGGGGTAAAATACCTIGAGCGGGCCAAAGTTGGGCGCGGTTGCTGGTT CGACCCAGCCATTGGCGGCGAAAGTCAGGCTGTGTICGCCGCAACCA TOCOCTCTTGCGGGGCAAGCTGGTTCGACAACGCATTGGCATAAGTCG TCOCCTCTIGCGGGGCAAGCTGGTCGACAACGCATIGGCATAAGTCG CAATCCOCGCOGCATGCAGCGCGTCCATACOGCCCATCTIGTCCTGAT
GCGCGTGAGTCACCACOGCCAGCGCGACOGGCAGGTTATCTCCTGCT TGATCCAGTTGAGGATCTGGGCGGTC

\section{AMIINOACIDELAST}

IVRDGGRVLVVDTAWIDDQTAQILNWIKQEINI PVALAVVIHAHQDKM GGMDALHAAGIATYANAISNQ APQBGMVAAQHST.TFAANGWVPATA PNFGFI KVFYPGPGHINDNITVGIDGWIAFGGCIIKDS

\section{NDM-1}

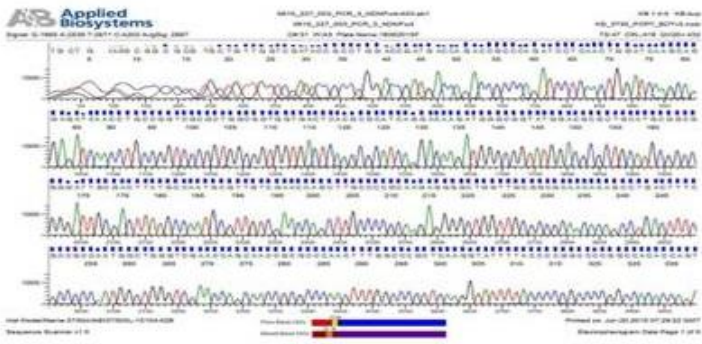

>0615_207_14_AMARIICON-3

TITGCTGTIGGTCGATACOGCCTGGACOGATGACCAGACOGCOCAGA TCCTCAACTGGATCAAGCAGGAGATCAACCTGCOGGTOGCGCTGGCGG TGGTGACTCACGCGCATCAGGACAAGATGGGCGGTATGGACGCGCTG TGGTGACTCACGCGCATCAGGACAAGATGGGCGGTATGGACGCGCTG CATGCGGCGGGGATMGGACTIATGCAATGCGITGCGAACCAGCT GCCOCGCAAGAGGGGCTGGTIGCGGCGCAACACAGCCTGACTICGCC GCCAATGGCTGGGTCGAACCAGCAACCGCGCOCAACTITGGCOCGCTC
AAGGTATITACOCOGGCCOCGGCCACACCAGTGACAATATCACOGT GGGATCGACGGCACCGACATCGCTITGGTGGCTGCCTGATCAAGGAC AGCAAGGC

\section{AMITOACID ER.AST}

З.LVDTAWIDDQTAQILNWIKQEINI PVALAVVTHAHQDKMGGMALH AAGIATYANALSNQLAPQEGLVAAQHS.TFAANGWVPATAPNFGH KV FYPGPGHINDNITVGIDGTIAFGGCIIKDSKA

\section{NDM-5}


Fig.3 DNA DNA sequencing results of amplified NDM-1

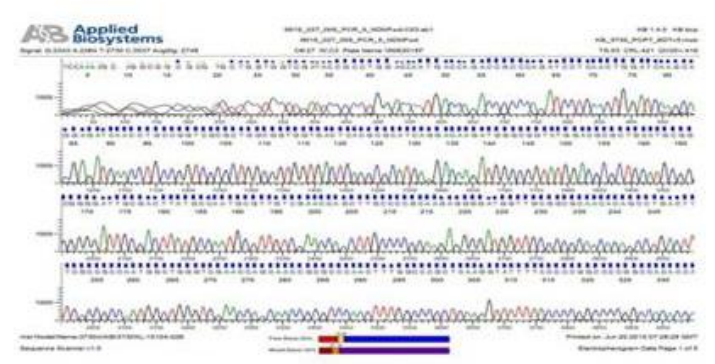

30615227 14 AMIFICON-5

CTGGTGGTCOAATACGCCTGGACCAATGACCAGACCGCCCAGATC CTCAACTGGATCAAGCAGGAGATCAACCTGCCGGTCGCGCTGGOG GTGGTGACTCACGCGCATCAGGACAAGATGGGCGGITGGACGC GCTGCATGCGGCGGGGATTGCGACTIATGCCAATGCGTIGTCGAA CCAGCTIGCCCCGCAAGAGGGGATGGTIGCGGCGCAACACAGCCT GACTITCGCCGCCAATGGCTGGGTCGAACCAGCAACCGCGCCCAA CTITGGCOCGCTCAAGGIATITACOCOGGCCCCGGCCACACCAGT CTITGGCCCGCTCAAGGIATTIACCOCGGCCCCGGCCACACCAGT GGCTGCCTGATCAAGGACAGC

\section{AMIINOACID F. AST}

LVVDTAWTKDOTAOILWWIKOEINI PVALAVVTHAFOD ALHAAGIATYANAISNQLAFQEGMVAAQHSIFAANGWVEPATAP NFGIXVFYPGPGISDNITVGIDGIDIAFGGCIIKDS

NDM-3

In a similar study from south India, NDM-1 was detected in $75 \%$ of $\mathrm{K}$. pneumoniae and $66 \%$ of E. coli by PCR and the remaining isolates were assumed to posses other mechanisms of resistance like efflux pumps, other carbapenamases, Amp C production and membrane impermeability (Nagaraj et al., 2012). DNA and protein sequencing were started in the 1970s, when the virus Lambda (50,000 nucleotides) was sequenced by Sanger et al., DNA sequencing was initially carried out for small genomes such as viruses and organelles, and complete sequencing of a bacterial genome were started later on with the improvements in sequencing technologies. DNA mutations has resulted in changes in the amino acid sequences and produced an ever increasing range of subtypes or variants in each of carbapenamase.

Fifteen variants of NDM-1 have been identified. These variants were identified after sequencing and blasting. They differ by
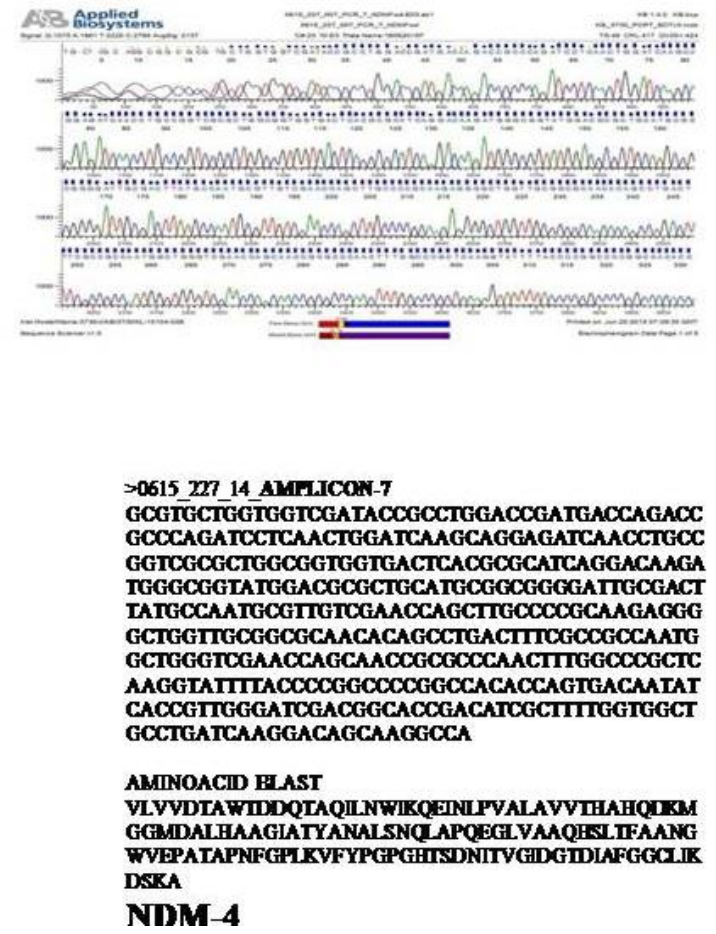

various aminoacid substitutions. We found NDM-1 in 5 strains (56\%), NDM-4 in 2 strains $(22 \%)$ NDM-3and NDM-5 in one strains each $(11 \%)$. Further characterization of the 18 strains (5 were Escherichia coli and 13 Klebsiella pneumoniae which were negative for NDM-1 gene) for the mechanism of resistance was not done in our study. These isolates probably have other carbapenemases like VIM or it may have efflux changes or Amp $\mathrm{C}$ beta lactamase production with outer membrane impermeability.

Presently NDM-1 producing bacterial infections can be managed with Colistin and Tigecycline combination. Colistin should not be given alone as it provokes resistance in vivo due to hetero resistant strains. Fosfomycin may also serve as an option for combination therapy. Detection of NDM-1 like carbapenemases in members of Enterobacteriaceae will help in the management and prevention of spread of such 
bacteria in hospital and community which in turn will save the patients and valuable drugs. Besides epidemiological surveillance sequencing would help to identify new drug targets, which can be used in the design of novel antibiotics.

\section{Acknowledgements}

I thank Dr. S. Ramalingam and Dr. B. Appalaraju for permitting me to carry out the work in the Department of Microbiology, PSG IMS\&R, Coimbatore. I acknowledge the kind help rendered by the supervisor Dr. B. Appalaraju for having guided at every level.

\section{References}

Berrazeg, M., S. Diene, L. Medjahed, P. Parola, M. Drissi, Didier Raoult, and J. Rolain. 2014. "New Delhi Metallo-beta-lactamase around the world: an eReview using Google Maps." Euro Surveill., 19, no. 20.

BorA, Arijit, and GiA Suddin AhMed. 2012. "Detection of NDM-1 in Clinical Isolates of Klebsiella pneumoniae from Northeast India." J. Clin. Diag. Res., 6, no. 5, 794800.

Bush, Karen, and George A. Jacoby. 2015. "Updated Functional Classification of BLactamases" Antimicrobial Agents and Chemotherapy, 54(3): 969-976.

Deshpande, P., Rodrigues, C., Shetty, A., Kapadia, F., Hedge, A., Soman, R. 2010. New Delhi Metallo-beta lactamase (NDM1) in Enterobacteriaceae: Treatment options with carbapenems compromised. J. Assoc. Physicians India, 58: 147-9.

Jeremiah, S.S., V. Balaji, S. Anandan, and R.D.
Sahni. 2014. A possible alternative to the error prone modified Hodge test to correctly identify the carbapenemase producing Gram-negative bacteria. Indian J. Med. Microbiol., 32, no. 4: 414.

Krishna, B.V. 2010. New Delhi metallo-betalactamases: a wake-up call for microbiologists. Indian J. Med. Microbiol., 8(3): 265-6.

Kumarasamy, K.K., Toleman, M.A., Walsh, T.R., et al. 2010. "Emergence of a new antibiotic resistance mechanism in India, Pakistan, and the UK: a molecular, biological, and epidemiological study". Lancet Infect. Dis., 10(9): 597-602.

Longo, Dan, Anthony Fauci, Dennis Kasper, and Stephen Hauser. 2011. Harrison's Principles of Internal Medicine 18th edition.McGraw-Hill Professional, 18 th edition $\mathrm{p}$ 1251-54.

Nagaraj, S., S.P. Chandran, P. Shamanna, and R. Macaden. 2012. "Carbapenem resistance among Escherichia coli and Klebsiella pneumoniae in a tertiary care hospital in south India." Indian J. Med. Microbiol., 30, no. 1: 93.

Nosocomial burn wound infections. 2004. In: Hospital Epidemiology and Infection Control, 4th ed.Mayhall CG, ed. Lippincott Williams and Wilkins, Philadelphia, 495497.

Queenan, A.M., Bush, K. 2007. Carbapenemases, The versatile $\beta$-lactamases, Clin. Microbiol. Rev., 20: 440-58.

Sanger, Frederick, Steven Nicklen, and Alan R. Coulson. 1977. "DNA sequencing with chain-terminating inhibitors."Proceedings of the National Acad. Sci., 74, no. 1: 54635467.

\section{How to cite this article:}

Uma Maheswari, M. and Appalaraju. 2017. Molecular Detection and Subtyping of Newdelhi Metallobetalactamases (NDM-1) in Clinical Isolates of Escherichia coli and Klebsiella pneumoniae in a Tertiary Care Hospital, South India. Int.J.Curr.Microbiol.App.Sci. 6(5): 22642270. doi: https://doi.org/10.20546/ijcmas.2017.605.252 